\title{
First-line treatment of patients with advanced or metastatic squamous non-small cell lung cancer: systematic review and network meta-analysis
}

\author{
Lisa M. Hess ${ }^{1}$, Amy M. DeLozier ${ }^{1}$, Fanni Natanegara ${ }^{1}$, Xiaofei Wang ${ }^{1}$, Victoria Soldatenkova ${ }^{2}$, \\ Alan Brnabic ${ }^{3}$, Stephen L. Able ${ }^{1}$, Jacqueline Brown ${ }^{4}$
}

${ }^{1}$ Eli Lilly and Company, Indianapolis, Indiana, USA; ${ }^{2}$ Lilly Deutschland GmbH, Bad Homburg, Germany; ${ }^{3}$ Eli Lilly and Company, West Ryde, NSW, Australia; ${ }^{4}$ Eli Lilly and Company, Windlesham, Surrey, UK

Contributions: (I) Conception and design: AM DeLozier, SL Able, J Brown, LM Hess; (II) Administrative support: None; (III) Provision of study materials or patients: None; (IV) Collection and assembly of data: AM DeLozier, LM Hess, SL Able; (V) Data analysis and interpretation: F Natanegara, X Wang, V Soldatenkova, A Brnabic, LM Hess, J Brown; (VI) Manuscript writing: All authors; (VII) Final approval of manuscript: All authors.

Correspondence to: Jacqueline Brown, PhD. Eli Lilly \& Company, Erl Wood Manor, Sunninghill Road, Windlesham, Surrey, GU20 6PH, UK.

Email: jackie.brown@lilly.com.

Background: The objectives of this systematic review and meta-analysis were to compare the survival, toxicity, and quality of life of patients treated with necitumumab in combination with gemcitabine and cisplatin. These agents were investigated in published randomized controlled trials (RCTs) of patients with squamous non-small cell lung cancer (NSCLC) in the first-line setting.

Methods: The systematic review was executed on January 27, 2015, and updated on August 21, 2016, using a pre-specified search strategy. Searches were conducted using PubMed, Medline, and EMBASE, with supplemental searches using the Evidence Based Medicine Reviews and ClinicalTrials.gov to identify RCTs published in English from 1995-2016 and reporting at least one of the primary outcomes [overall survival (OS), progression-free survival (PFS), toxicity, or quality of life] in patients who received first-line treatment for advanced or metastatic squamous NSCLC. Study quality and risk of bias were assessed using the Physiotherapy Evidence Database (PEDro) scale and Cochrane risk of bias tool, respectively. A Baysian network meta-analysis was performed on the primary outcomes. Hazard ratios (HRs) were evaluated for the primary analysis; secondary analyses were conducted using median OS data. Planned sensitivity analyses were conducted including reanalysis using a Frequentist approach and limiting analyses to subsets based on clinical and demographic covariates.

Results: The systematic literature review resulted in identification of 4,016 unique publications; 40 publications (35 unique trials) were eligible for inclusion. Eight studies connected to a common network for the OS analysis using HR data. The majority of studies were not limited to squamous NSCLC, thus analyzable data were limited to a subset of data within the published trials. Carboplatin $+\mathrm{S}-1$ and necitumumab in combination with gemcitabine and cisplatin were associated with lower HRs for OS versus all other comparators. Nine studies connected to the network for the PFS analysis in which necitumumab in combination with gemcitabine and cisplatin was associated with the lowest HR. Data were not available to analyze toxicity or quality of life.

Conclusions: Although the results suggest that carboplatin + S-1 and necitumumab in combination with gemcitabine and cisplatin may have value in terms of OS versus other comparators, the results should be interpreted with caution due to the limited number of studies (with few focused exclusively on squamous NSCLC) and wide credible intervals. 
Keywords: Non-small cell lung cancer (NSCLC); chemotherapy; squamous; network meta-analysis; necitumumab; S-1

Submitted Jan 12, 2018. Accepted for publication Nov 12, 2018.

doi: $10.21037 /$ jtd.2018.11.87

View this article at: http://dx.doi.org/10.21037/jtd.2018.11.87

\section{Introduction}

Approximately $30 \%$ of all non-small cell lung cancers (NSCLCs) are of squamous cell histology $(1,2)$. Histologyspecific treatment is a relatively new development in NSCLC that initiated with the Food and Drug Administration's approval of pemetrexed in 2004 for the second-line treatment of non-squamous NSCLC (3). Metastatic squamous NSCLC is more difficult to treat compared with non-squamous disease. Patients with squamous NSCLC have higher rates of smoking-related and other comorbidities and have lower survival rates than patients with non-squamous $\operatorname{NSCLC}(4,5)$.

The standard treatment of squamous NSCLC in the first-line setting has been limited to doublet, platinumbased regimens $(6,7)$. Trials of many new agents have failed in the squamous NSCLC population due to safety concerns and/or a lack of efficacy, resulting in few advancements for the treatment of squamous NSCLC (8). In contrast, patients with non-squamous NSCLC have benefited from pemetrexed and bevecizumab as first-line or maintenance treatments as well as from targeted drugs for epidermal growth factor receptor (EGFR) mutations and anaplastic lymphoma kinase $(A L K)$ translocations (9). A benefit for nab-paclitaxel in the treatment of squamous NSCLC has been reported (10); of note, interim data from the phase III KEYNOTE-407 (NCT02775435) study in patients with previously untreated advanced squamous NSCLC recently showed an improvement in the overall survival (OS) of patients treated with pembrolizumab combined with carboplatin plus either paclitaxel or nab-paclitaxel compared with chemotherapy alone $(11,12)$. Nonetheless, contrary to the advancements made in the treatment of metastatic nonsquamous NSCLC in the first-line setting and the superior efficacy of immune checkpoint inhibitors in the second-line setting, first-line treatment of squamous NSCLC has shown relatively little improvement in the past 20 years $(8,13)$.

Thus, there is a need for more effective first-line treatments for patients with squamous NSCLC. Necitumumab is a second-generation, recombinant, human immunoglobulin G1 EGFR monoclonal antibody that binds to EGFR with high affinity and prevents receptor activation and downstream signaling by competing with natural ligands. It was studied in the phase III SQUIRE trial (ClinicalTrials.gov identifier: NCT00981058) for the treatment of patients with stage IV (metastatic) squamous NSCLC and an Eastern Cooperative Oncology Group (ECOG) performance status (PS) of 0-2 (14). The SQUIRE trial was a randomized, multicenter, open-label, phase III trial of cisplatin (cis) + gemcitabine (gem) with or without necitumumab (neci) for first-line treatment of patients with stage IV squamous NSCLC. OS, the primary endpoint in the SQUIRE trial, for the neci + cis + gem $(n=545)$ arm was significantly longer compared with cis + gem alone [hazard ratio (HR) $0.84,95 \%$ confidence interval (CI): 0.74-0.96; $\mathrm{P}=0.01$; median, 11.5 months, 95\% CI: 10.4-12.6 months; vs. 9.9 months, $95 \%$ CI: 8.9-11.1 months]. There were also statistically significant improvements in progression-free survival (PFS) for neci + gem + cis compared with gem + cis (HR, $0.85,95 \%$ CI: $0.74-$ 0.98; $\mathrm{P}=0.02$; median 5.7 months, $95 \%$ CI: 5.6-6.0 months; vs. 5.5 months, $95 \%$ CI: $4.8-5.6$ months) (14).

The objectives of this systematic literature review and meta-analysis were to compare the clinical efficacy (OS and PFS), quality of life (QOL), and safety outcomes (toxicity) of neci + gem + cis with other first-line treatments that have been studied in randomized controlled trials (RCTs) including patients with squamous NSCLC. This study was registered in the PROSPERO registry (CRD42014008968), and the study protocol was published prior to the conduct of the research (15).

\section{Methods}

\section{Search strategy}

The study was designed in accordance with the Preferred Reporting Items for Systematic reviews and Meta-Analyses (PRISMA) guidelines (16,17). A systematic literature review was conducted using a pre-specified search strategy in PubMed, Medline, and EMBASE. A supplemental search was conducted using the Evidence Based Medicine (EBM) 
Reviews and ClinicalTrials.gov. The goal of the search was to identify RCTs that reported at least one of the prespecified primary outcomes (OS, PFS, toxicity, or QOL) for patients who received first-line treatment for advanced or metastatic squamous NSCLC. The search strategy focused on PICOT (patients, interventions, comparators, outcomes, timing) terms, and detailed search strategies used in each database are provided in the published study protocol (15). A manual search of reference lists of systematic reviews and other review articles was conducted to ensure no eligible RCTs were omitted. The search strategy was conducted on January 27, 2015 and was updated on August 21, 2016.

\section{Eligibility criteria and assessment}

Based on the PICOT criteria, eligible studies included the following: (I) participants with a diagnosis of advanced or metastatic squamous NSCLC who had not received any prior chemotherapy treatment for the disease; (II) interventions and comparators with either market authorization for use in NSCLC or that were recommended by clinical treatment guidelines for patients with advanced or metastatic squamous NSCLC in the first-line setting; (III) one or more of the following outcomes for the squamous NSCLC population: OS, PFS, toxicity, or QOL; a time period limited to 1995-2016 to ensure publication occurred during the period in which histological differentiation was known for NSCLC; and an RCT study design. An additional inclusion criterion was publication in English. Studies investigating radiation therapy were excluded.

Abstracts of publications identified in the literature search were dual reviewed and excluded if it was determined that eligibility criteria were not met. Two independent reviewers reviewed the full text of all remaining publications for eligibility. A third reviewer who was not directly involved in the eligibility assessment reviewed articles determined to be eligible to ensure accuracy.

\section{Data extraction}

Two reviewers independently extracted data elements from each publication meeting eligibility criteria. The variables extracted from eligible publications are included in the published study protocol (15). Briefly, these variables included details of the published source; clinical and demographic characteristics of the squamous NSCLC population; study design; treatments assigned; and all
OS, PFS, QOL, and toxicity outcome data. To ensure the accuracy of the extracted data, after dual review and validation, an individual not involved in the original dataextraction process verified a subset of $10 \%$ of all extracted articles. Authors of publications with limited data (e.g., median but no HR, survival curves but no data values) were contacted via email to enhance the quality and quantity of available data.

\section{Study quality and bias assessment}

The Physiotherapy Evidence Database (PEDro) scale (18) and the Cochrane risk of bias tool (19) were used to assess study quality and bias, respectively. Two reviewers independently assessed each study using these tools; quality and bias data from the independent reviewers were compared. If any data element did not match, the reviewers attempted to resolve the discrepancies. In the event of differing opinions, a third reviewer was consulted to reach consensus.

\section{Statistical analysis}

\section{Analysis plan}

Study analyses were performed using SAS version 9.4 (SAS Institute, Cary, NC, USA), R version 3.0.2 R Package netmeta, and WinBUGS 1.4.33. The network meta-analysis of OS and PFS used HR and $95 \%$ CI data reported in the primary publications. Kaplan-Meier survival curves were digitized for all studies; however, the HRs obtained from these methods were used in the analysis only if HR data were missing in the primary publication. The combination of neci + gem + cis was used as the comparator in analyses to evaluate its effectiveness versus other treatment regimens, as per the primary objective of this study. A Bayesian network meta-analysis was performed (20), whereby the $95 \%$ credible interval (CrI) can be interpreted as a $95 \%$ probability that the true value of the HR lies within the calculated interval. When the CrI does not cross 1 , there is a high degree of certainty that the results favor the treatment with the lower hazard. The probability rankings are based on the HR difference and represent the average of rankings across posterior samples of the HR difference. In fixed-effects meta-analyses, the assumption is that the included clinical trials share a common effect size, whereas in random-effects models the true treatment effects are assumed to vary among studies and the data are considered 
a random sample of the true treatment effect (20).

For studies that did not report a HR or provide a Kaplan-Meier curve but did provide data on median survival, secondary analyses were conducting using the log transformation of the median survival data as the outcome to enhance the network of studies for the survival (OS and PFS) outcomes. In the case of missing standard error (SE) data, the SE was estimated from the median time to event; this estimation assumed an exponential distribution of survival time and $\log (\mathrm{HR})=-\log$ (median time ratio) (21). Results are presented as median survival with $95 \%$ CrI.

\section{Covariates}

The covariates of age (median age) and stage (percentage of patients with stage IV disease) were included in planned adjusted analyses because these variables have prognostic value in squamous NSCLC. Additional covariates of gender (percentage male) and performance status (percentage with ECOG PS of 0 or 1) were identified in the systematic literature review and were included in post-hoc analyses to control for potential heterogeneity among trials. Both the primary (HR) and secondary (median survival) analyses for OS and PFS were conducted as planned unadjusted and adjusted analyses using these covariates. Due to limited data, in cases without treatment arm-specific squamous patient data on the covariates, the overall squamous subset data on covariates were used. In cases without squamous-specific covariate data, the overall study data on the covariates by treatment arm were used to populate the covariate data. No estimates were made for missing covariate data that were not included in the eligible study publication.

\section{Heterogeneity and inconsistency evaluation}

The forest plot for each outcome was visually inspected for evidence of heterogeneity. The consistency assumption was explored by a prespecified visual examination of the network diagrams. Density plots of posterior samples were compared from models (using direct, indirect, and mixed evidence). Lastly, variance and standard deviation (heterogeneity parameters) and residual deviance and Deviance Information Criterion, which is a Bayesian criterion for model comparison (model fit) between the random-effects and fixed-effects models, were also explored.

\section{Sensitivity analyses}

Several sensitivity analyses were designed a priori to test the robustness of the findings. The analysis was re-run using the Frequentist methods of Rücker and Krahn et al.
$(22,23)$. Additionally, an analysis was conducted to evaluate the findings using HR versus median time-to-event data. Additional analyses were conducted to evaluate the findings under the following scenarios: only including patients with metastatic (stage IV) disease; excluding indirect comparisons; limiting to phase III trials; only including studies with older patients (mean age $>70$ years); only including high- and low-quality studies (PEDro scale value $>6$ and $\leq 6$, respectively); and lastly, excluding studies with bias identified using the Cochrane risk of bias tool.

In order for the analysis to be relevant to regions beyond Asia, in which carboplatin (carbo) $+\mathrm{S}-1$ is not a treatment that is approved or used, reference to carbo $+\mathrm{S}-1$ was removed in a secondary analysis for data submission to reimbursement bodies beyond Asia (e.g., National Institute for Health and Care Excellence in the UK).

\section{Results}

\section{Study identification}

The systematic literature review resulted in the identification of 4,016 unique publications. Of these, 2,715 were eliminated from further analysis by screening the study abstract. Full-text review of 1,301 articles was completed, and an additional 1,263 publications were excluded (Figure 1). A total of 40 publications, representing 35 clinical trials, were eligible for this study.

\section{Study quality and bias assessment}

According to the PEDro methodology quality criteria, only 3 clinical trials included in the systematic literature review were categorized as low quality, having a PEDro scale value of $\leq 6$ (24-26). The criteria most frequently rated as negative were those associated with blinding. Only 10 trials reported adequate blinding of patients.

Results from Cochrane assessments of the risk of bias were similar to results from the PEDro methodological scale. Studies were most commonly categorized as high risk because of inadequate blinding. Studies were generally categorized as low risk per the remaining Cochrane criteria. More detailed results of the study quality and risk of bias assessment for the 35 trials are presented in Table S1.

\section{Characteristics of eligible studies}

The basic characteristics, including the comparators and 


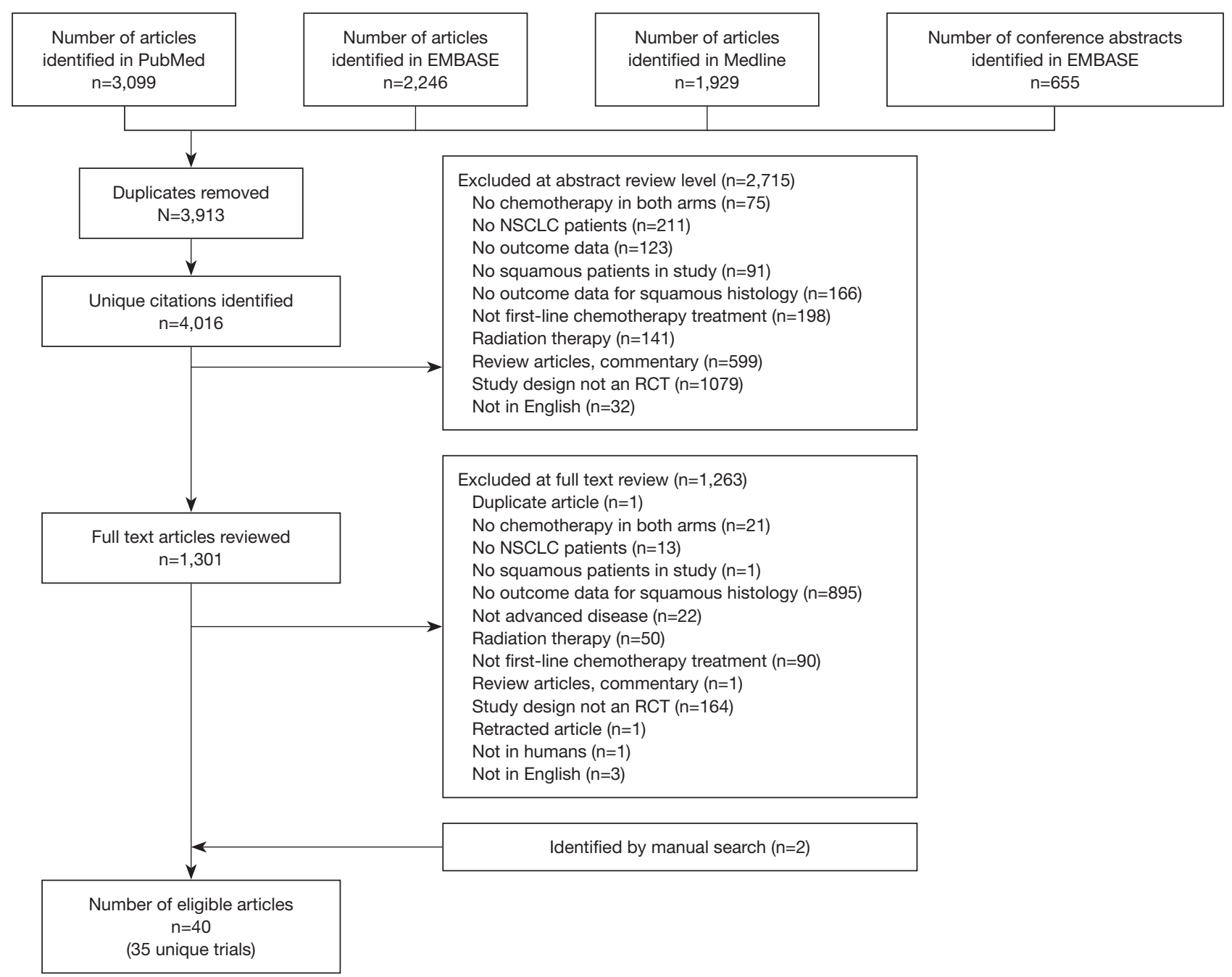

Figure 1 PRISMA diagram. NSCLC, non-small cell lung cancer; RCT, randomized, controlled trial.

size of the squamous population, of all eligible studies are included in Table 1. Only three of the studies were phase II trials $(27,29,61)$. The majority of the trials included were not limited to squamous NSCLC. Of the 35 trials (40 publications), only 12 (14 publications) connected to the study network for OS or PFS (Figure 2). Reasons why trials were excluded from the analysis were as follows: lack connection to the network through a common comparator $(n=4)$; investigation of experimental agents without market authorization or not recommended for use (e.g., by treatment guidelines) in any country $(\mathrm{n}=11)$; agents currently limited to use in non-squamous NSCLC (e.g., all pemetrexed- or bevacizumab-containing regimens deemed ineffective and/or with safety concerns in patients with squamous tumors; $\mathrm{n}=6$ ); or agents not prescribed as care for patients with NSCLC $(n=1)$. An additional study was excluded from the analysis because it investigated two dosing schedules of the same regimen $(\mathrm{n}=1)$.

When study covariates (Table 2) were included, the adjusted models failed to converge because of the small number of studies. Therefore, unadjusted models were used for all analyses in this report. A limited number of studies were identified, resulting in limited evidence for each comparator in the network (e.g., most had data from only one trial). Because of the limited evidence and few patients, the random-effects heterogeneity variance became inestimable and the random-effects models failed to converge. As a result, it was required to conduct study analyses using a fixed-effects model. 
Table 1 Characteristics of the 35 eligible clinical trials and reasons for inclusion in or exclusion from analyses

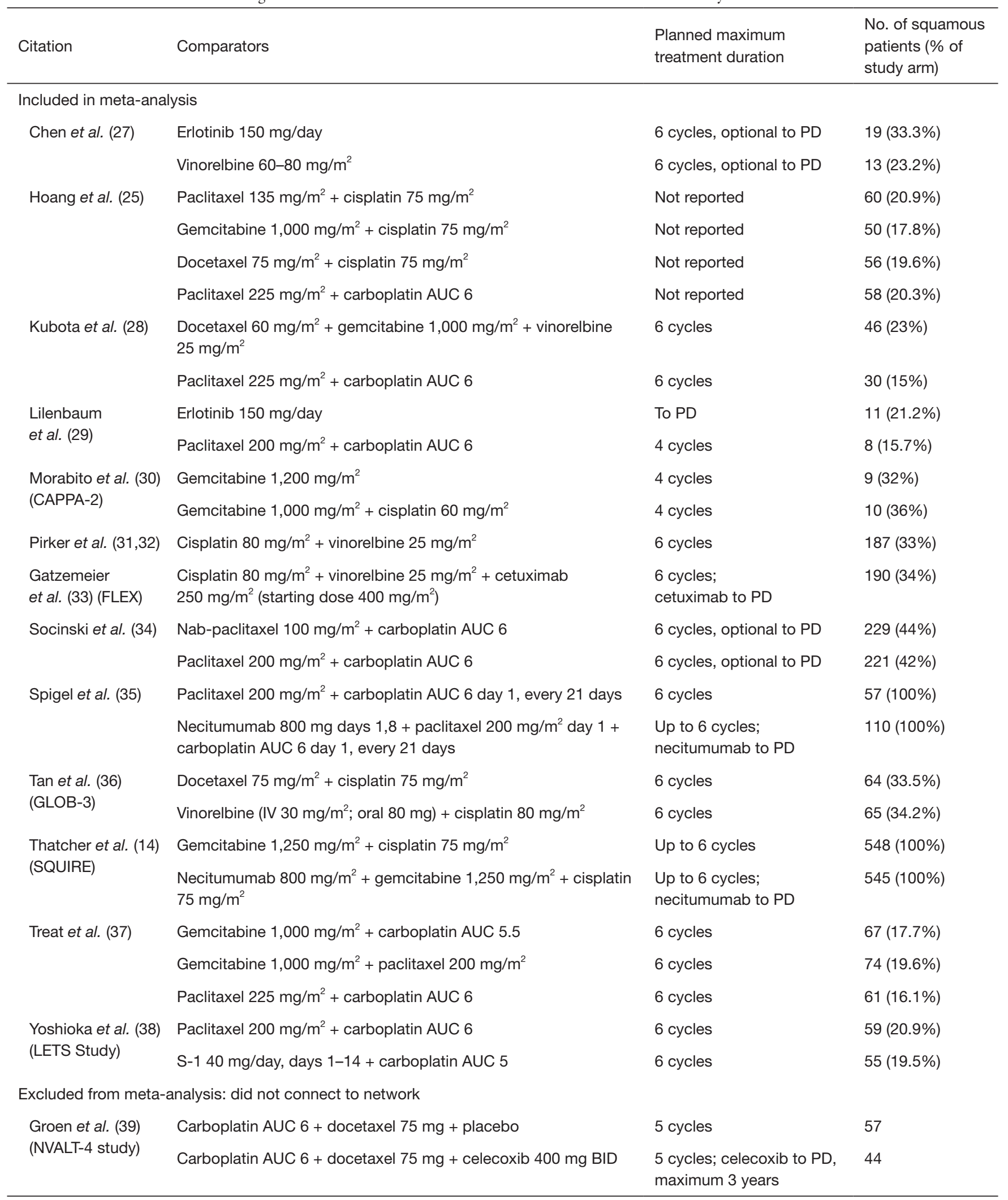

Table 1 (continued) 
Table 1 (continued)

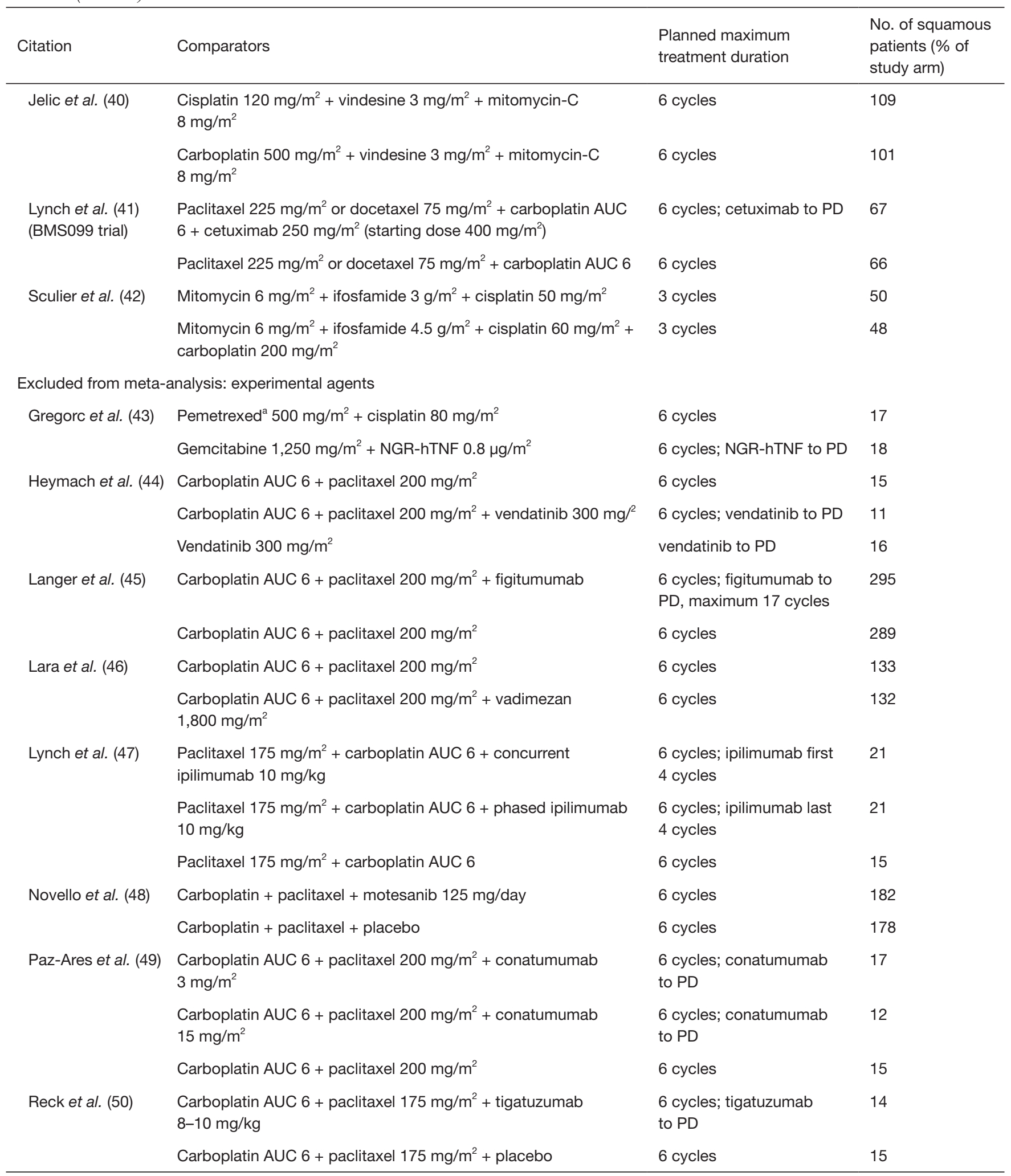

Table 1 (continued) 
Table 1 (continued)

\begin{tabular}{|c|c|c|c|}
\hline Citation & Comparators & $\begin{array}{l}\text { Planned maximum } \\
\text { treatment duration }\end{array}$ & $\begin{array}{l}\text { No. of squamous } \\
\text { patients (\% of } \\
\text { study arm) }\end{array}$ \\
\hline Scagliotti et al. (51) & $\begin{array}{l}\text { Carboplatin AUC } 6 \text { + paclitaxel } 200 \mathrm{mg} / \mathrm{m}^{2}+\text { sorafenib } 400 \mathrm{mg} \\
\text { BID }\end{array}$ & 6 cycles; sorafenib to PD & 109 \\
\hline $\begin{array}{l}\text { von Pawel et al. (52) } \\
\text { (DISRUPT) }\end{array}$ & $\begin{array}{l}\text { (Docetaxel } 75 \mathrm{mg} / \mathrm{m}^{2}+\text { cisplatin } 75 \mathrm{mg} / \mathrm{m}^{2} \text { ) or (carboplatin AUC } 6 \\
\left.\text { + paclitaxel } 200 \mathrm{mg} / \mathrm{m}^{2}\right)+ \text { placebo }\end{array}$ & 6 cycles & 29 \\
\hline Spigel et al. (26) & $\begin{array}{l}\text { Gemcitabine } 1,000 \mathrm{mg} / \mathrm{m}^{2}+\text { carboplatin AUC } 5+\text { iniparib } \\
5.6 \mathrm{mg} / \mathrm{kg}\end{array}$ & 6 cycles, optional to PD & 390 \\
\hline \multirow[t]{2}{*}{$\begin{array}{l}\text { Govindan et al. (24) } \\
\text { (CALGB 30407) }\end{array}$} & $\begin{array}{l}\text { Pemetrexed } 500 \mathrm{mg} / \mathrm{m}^{2}+\text { carboplatin AUC } 5+\text { thoracic radiation } \\
70 \text { Gy }\end{array}$ & 4 cycles & 17 \\
\hline & $\begin{array}{l}\text { Pemetrexed } 500 \mathrm{mg} / \mathrm{m}^{2}+\text { carboplatin AUC } 5+\text { cetuximab } \\
\left.250 \mathrm{mg} / \mathrm{m}^{2} \text { (starting dose } 400 \mathrm{mg} / \mathrm{m}^{2}\right)+ \text { thoracic radiation } 70 \text { Gy }\end{array}$ & 4 cycles & 18 \\
\hline \multirow[t]{2}{*}{ Sandler et al. (53) } & Paclitaxel 200 mg/m² + carboplatin AUC 6 & 6 cycles & 2 \\
\hline & $\begin{array}{l}\text { Paclitaxel } 200 \mathrm{mg} / \mathrm{m}^{2}+\text { carboplatin AUC } 6 \text { + bevacizumab } \\
15 \mathrm{mg} / \mathrm{m}^{2}\end{array}$ & $\begin{array}{l}6 \text { cycles; bevacizumab } \\
\text { to PD }\end{array}$ & 1 \\
\hline Scagliotti et al. (54) & Pemetrexed 500 mg/m² + cisplatin 75 mg/m² & 6 cycles & 229 \\
\hline Novello et al. (55) & Gemcitabine $1,250 \mathrm{mg} / \mathrm{m}^{2}+$ cisplatin $75 \mathrm{mg} / \mathrm{m}^{2}$ & 6 cycles & 244 \\
\hline \multirow[t]{2}{*}{ Schuette et al. (57) } & Pemetrexed $500 \mathrm{mg} / \mathrm{m}^{2}+$ cisplatin $75 \mathrm{mg} / \mathrm{m}^{2}$ & 6 cycles & 12 \\
\hline & Pemetrexed 500 mg $/ \mathrm{m}^{2}$ + carboplatin AUC 6 & 6 cycles & 13 \\
\hline \multirow[t]{2}{*}{ Zhang et al. (58) } & Pemetrexed 500 mg/m² + cisplatin 75 mg/m² & 6 cycles & 22 \\
\hline & Gemcitabine $1,000 \mathrm{mg} / \mathrm{m}^{2}+$ cisplatin $75 \mathrm{mg} / \mathrm{m}^{2}$ & 6 cycles & 24 \\
\hline \multicolumn{4}{|c|}{ Excluded from meta-analysis: not used in NSCLC } \\
\hline \multirow[t]{2}{*}{ Lee et al. (59) } & $\begin{array}{l}\text { Gemcitabine } 1,200 \mathrm{mg} / \mathrm{m}^{2}+\text { carboplatin AUC } 6+\text { thalidomide } \\
(100-200 \mathrm{mg} / \text { day })\end{array}$ & $\begin{array}{l}4 \text { cycles; thalidomide } \\
2 \text { years }\end{array}$ & 124 \\
\hline & Gemcitabine $1,200 \mathrm{mg} / \mathrm{m}^{2}+$ carboplatin AUC 6 + placebo & 4 cycles & 115 \\
\hline \multicolumn{4}{|c|}{ Excluded from meta-analysis: same comparator in both arms } \\
\hline \multirow[t]{2}{*}{ Zwitter et al. (60) } & Gemcitabine $1,250 \mathrm{mg} / \mathrm{m}^{2}+$ cisplatin $75 \mathrm{mg} / \mathrm{m}^{2}$ & $\begin{array}{l}6 \text { cycles gemcitabine; } \\
4 \text { cycles cisplatin }\end{array}$ & 32 \\
\hline & Gemcitabine $250 \mathrm{mg} / \mathrm{m}^{2}+$ cisplatin $75 \mathrm{mg} / \mathrm{m}^{2}$ & $\begin{array}{l}6 \text { cycles gemcitabine; } \\
4 \text { cycles cisplatin }\end{array}$ & 39 \\
\hline
\end{tabular}

\footnotetext{
${ }^{\mathrm{a}}$, also not indicated in squamous cell carcinoma. NSCLC, non-small cell lung cancer; PD, progressive disease.
} 

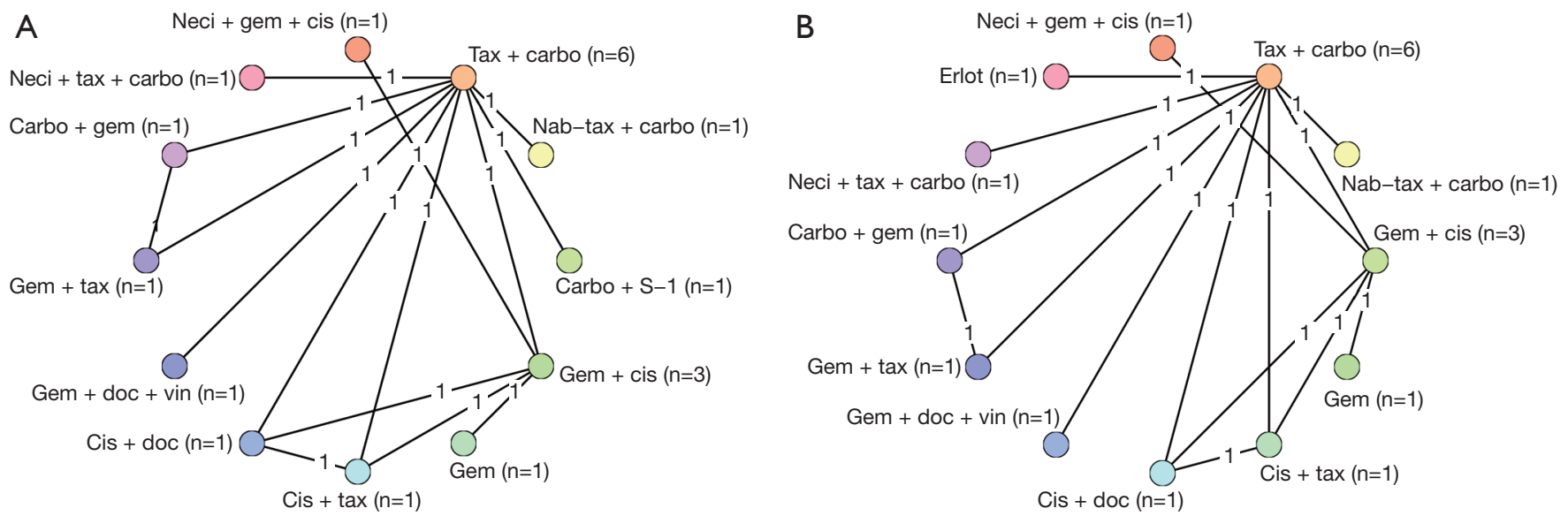

Figure 2 Network diagrams for hazard ratio analyses of overall survival (A) and progression-free survival (B). Carbo, carboplatin; cis, cisplatin; doc, docetaxel; erlot, erlotinib; gem, gemcitabine; nab-tax, nab-paclitaxel; neci, necitumumab; tax, paclitaxel; vin, vinorelbine.

\section{Proportional hazards}

The proportional hazards assumption was tested in a subset of eligible studies $(34,37,38,59)$ with OS or PFS curves that could be digitized to ensure there were no violations in the proportional hazards assumption of the models. The results demonstrated no evidence of violation of this assumption for available comparators, with a marginal result of $\mathrm{P}=0.056$ for carbo + paclitaxel (tax) vs. gem + carbo (37).

\section{OS}

Eight studies connected to a common network for the OS analysis using HR data $(14,25,28,30,34,37,38,61)$. All comparators, with the exception of carbo + S-1, were associated with a higher HR than neci + gem + cis. A very wide $\mathrm{CrI}$ for OS was observed in one study (30). Figure 3 presents the forest plots associated with the OS HR analysis, and the pairwise comparisons are provided in Figure 4. When including carbo $+\mathrm{S}-1$, the probability of neci + gem + cis being the highest ranked treatment option was $22.0 \%$, whereas the probability for carbo $+\mathrm{S}-1$ was $45.2 \%$. Neci + carbo + tax had a $17.3 \%$ probability, gem + docetaxel + vinorelbine had a $9.8 \%$ probability, and all others had less than a $5 \%$ probability of being the highest ranked OS option. When excluding the carbo $+\mathrm{S}-1$ regimen because this agent is not available beyond Asia and may not be a relevant comparator worldwide, neci + gem + cis had a $35.4 \%$ probability of being ranked first for OS, neci + carbo + tax had a $30.8 \%$ probability, gem + docetaxel + vinorelbine had a $18.5 \%$ probability, and nab-tax + carbo had a $10.8 \%$ probability. The full details of the probability rankings for OS with and without the S-1 regimen are included in Figures $S 1$ and $S 2$.

A number of studies reported neither HRs nor KaplanMeier curves. Median data were used in a pre-planned secondary analysis to expand the network $(14,25,32,34$, $36-38,61)$. The median analyses were conducted with tax + carbo as the reference comparator because the models did not converge when compared with neci + gem + cis. However, for all other analyses, data are provided versus neci + gem + cis whenever possible for consistency of reporting and interpretation of findings. Neci + gem + cis was associated with a longer survival time than the comparators other than carbo $+\mathrm{S}-1$. Pairwise comparisons (presented as posterior median differences with 95\% CrIs) are shown in Figure 4.

\section{PFS}

Nine studies connected to the network for the PFS HR analysis $(14,28-30,34,35,37,38,61)$. Neci + gem + cis demonstrated longer PFS compared with all other comparators. Figure $3 B$ presents the forest plots associated with the PFS HR analysis; the pairwise comparisons are provided in Figure 5. The probability of neci + gem + cis being the highest ranked for PFS in the HR analysis was $63.0 \%$. Nab-tax + carbo had an $11.1 \%$ probability, carbo + S-1 had an $11.0 \%$ probability, and gem + docetaxel + vinorelbine had a $6.5 \%$ probability. All other comparators had less than a $5 \%$ probability of being the highest ranked 
Table 2 Covariates for included studies in the network meta-analysis

\begin{tabular}{|c|c|c|c|c|c|}
\hline Included trial & Treatment arm & $\begin{array}{l}\text { Median } \\
\text { age, y }\end{array}$ & $\begin{array}{l}\text { Male, } \\
\%\end{array}$ & $\begin{array}{l}\text { Stage IV, } \\
\%\end{array}$ & $\begin{array}{c}\text { ECOG PS } \\
0-1, \%\end{array}$ \\
\hline Chen et al. (27) & Erlotinib 150 mg/day & $77^{\mathrm{a}}$ & $82.5^{\mathrm{a}}$ & $75.4^{\mathrm{a}}$ & $80.7^{\mathrm{a}}$ \\
\hline \multirow[t]{2}{*}{ Hoang et al. (25) } & Paclitaxel $135 \mathrm{mg} / \mathrm{m}^{2}+$ cisplatin $75 \mathrm{mg} / \mathrm{m}^{2}$ & 63 & 72.8 & 87.9 & 91.7 \\
\hline & Paclitaxel 225 mg/m² + carboplatin AUC 6 & 63 & 72.8 & 87.9 & 91.7 \\
\hline \multirow[t]{2}{*}{ Kubota et al. (28) } & Docetaxel $60 \mathrm{mg} / \mathrm{m}^{2}+$ gemcitabine $1,000 \mathrm{mg} / \mathrm{m}^{2}+$ vinorelbine $25 \mathrm{mg} / \mathrm{m}^{2}$ & $64^{\mathrm{a}}$ & $73^{\mathrm{a}}$ & $83^{\mathrm{a}}$ & 100 \\
\hline & Paclitaxel 225 mg/m² + carboplatin AUC 6 & $65^{\mathrm{a}}$ & $69^{\mathrm{a}}$ & $83^{\mathrm{a}}$ & 100 \\
\hline $\begin{array}{l}\text { Morabito et al. (30) } \\
\text { (CAPPA-2) }\end{array}$ & Gemcitabine $1,000 \mathrm{mg} / \mathrm{m}^{2}+$ cisplatin $60 \mathrm{mg} / \mathrm{m}^{2}$ & $63^{\mathrm{a}}$ & $82^{\mathrm{a}}$ & $93^{\mathrm{a}}$ & 0 \\
\hline Pirker et al. $(31,32)$ & Cisplatin $80 \mathrm{mg} / \mathrm{m}^{2}+$ vinorelbine $25 \mathrm{mg} / \mathrm{m}^{2}$ & $60^{\mathrm{a}}$ & $71^{\mathrm{a}}$ & $94^{\mathrm{a}}$ & $81^{\mathrm{a}}$ \\
\hline $\begin{array}{l}\text { Gatzemeier } \\
\text { et al. (33) }\end{array}$ & $\begin{array}{l}\text { Cisplatin } 80 \mathrm{mg} / \mathrm{m}^{2}+\text { vinorelbine } 25 \mathrm{mg} / \mathrm{m}^{2}+\text { cetuximab } 250 \mathrm{mg} / \mathrm{m}^{2} \\
\text { (starting dose } 400 \mathrm{mg} / \mathrm{m}^{2} \text { ) }\end{array}$ & $59^{\mathrm{a}}$ & $69^{a}$ & $94^{\mathrm{a}}$ & $84^{\mathrm{a}}$ \\
\hline \multirow[t]{2}{*}{ Socinski et al. (34) } & Nab-paclitaxel 100 mg/m² + carboplatin AUC 6 & $60^{\mathrm{a}}$ & $75^{\mathrm{a}}$ & $79^{\mathrm{a}}$ & $99.4^{\mathrm{a}}$ \\
\hline & Paclitaxel 200 mg/m² + carboplatin AUC 6 & $60^{\mathrm{a}}$ & $75^{\mathrm{a}}$ & $79^{\mathrm{a}}$ & $99.6^{a}$ \\
\hline Spigel et al. (61) & Necitumumab 800 mg + paclitaxel 200 mg/m² + carboplatin AUC 6 & 66 & 79.1 & 100 & 100 \\
\hline \multirow[t]{3}{*}{ Treat et al. (37) } & Gemcitabine $1,000 \mathrm{mg} / \mathrm{m}^{2}+$ carboplatin AUC 5.5 & 65.8 & 62.4 & 94.6 & 100 \\
\hline & Gemcitabine $1,000 \mathrm{mg} / \mathrm{m}^{2}+$ paclitaxel $200 \mathrm{mg} / \mathrm{m}^{2}$ & 65.8 & 62.4 & 94.6 & 100 \\
\hline & Paclitaxel 225 mg/m² + carboplatin AUC 6 & 65.8 & 62.4 & 94.6 & 100 \\
\hline \multirow{2}{*}{$\begin{array}{l}\text { Yoshioka et al. (38) } \\
\text { (LETS Study) }\end{array}$} & Paclitaxel 200 mg/m² + carboplatin AUC 6 & 65 & 86.4 & 54.2 & 100 \\
\hline & $\mathrm{S}-140 \mathrm{mg} /$ day, days $1-14$ + carboplatin AUC 5 & 66 & 87.3 & 63.6 & 100 \\
\hline
\end{tabular}

a , from the overall study; not specific to the squamous subset. EGOC PS, Eastern Cooperative Oncology Group performance status; IV, intravenous.

for PFS. When excluding carbo $+\mathrm{S}-1$, neci + gem + cis had a $70.8 \%$ probability of being the highest ranked option for PFS, nab-tax + carbo had a $12.7 \%$ probability, gem + docetaxel + vinorelbine had a $7.0 \%$ probability, and all other comparators had less than a $5 \%$ probability. Probabilities of
PFS treatment rankings with and without the carbo $+\mathrm{S}-1$ regimen are included in Figures $S 3$ and $S 4$.

Similar to the OS analyses, numerous studies did not report PFS HRs and Kaplan-Meier curves, and median PFS data were used to expand the network by seven studies 
A Post. median effect of active treatments vs. Neci+gem+cis

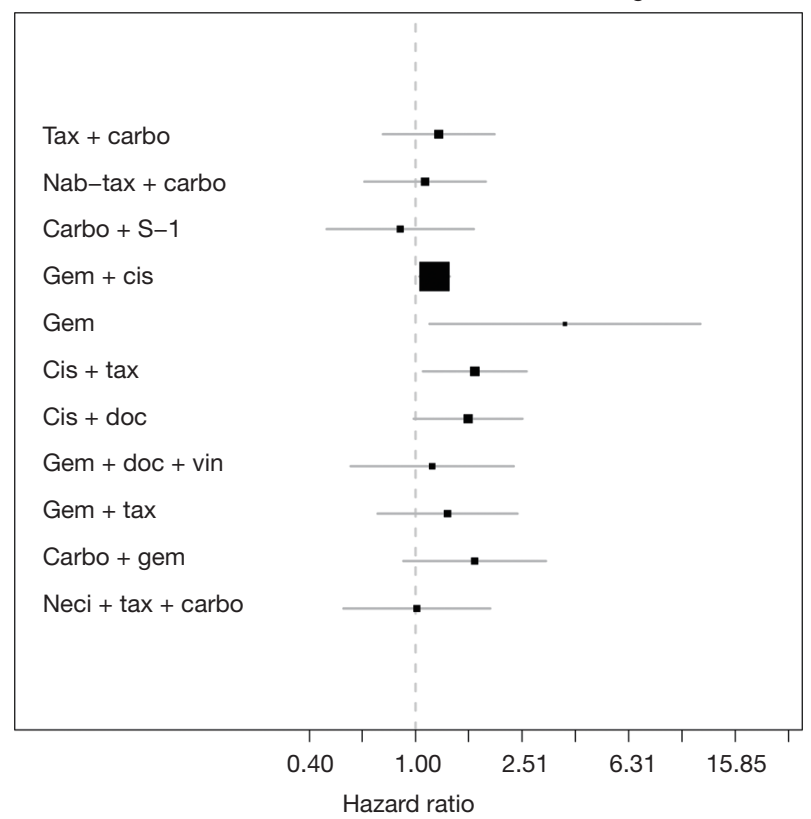

95\% Crl with boxes indicating the sample size/precision

B

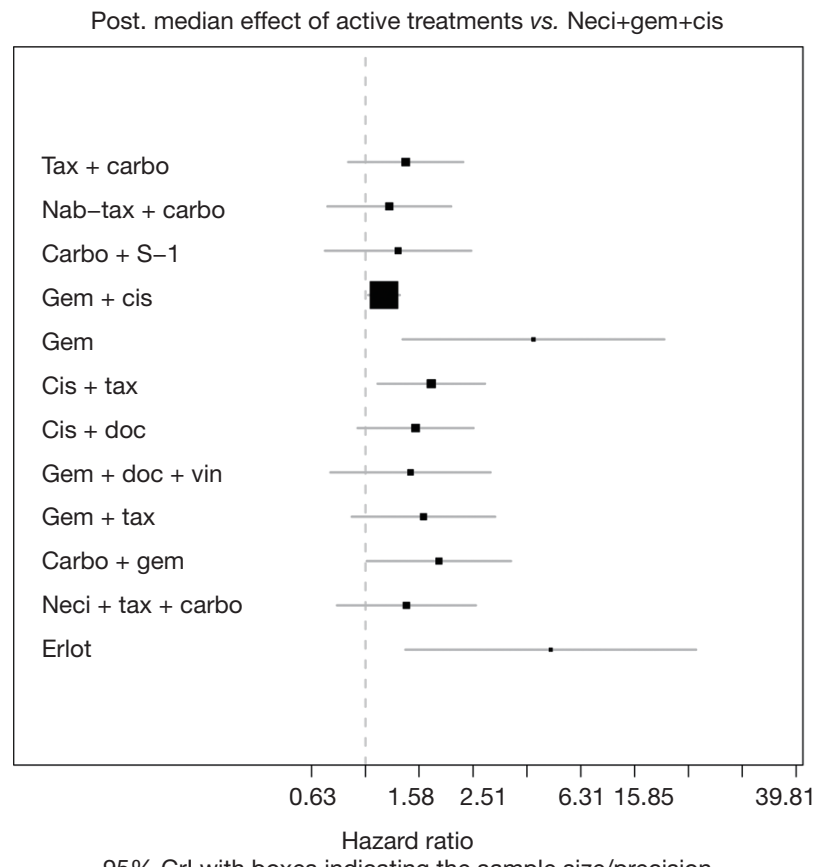

Post. median effect of active treatments vs. Neci+gem+cis

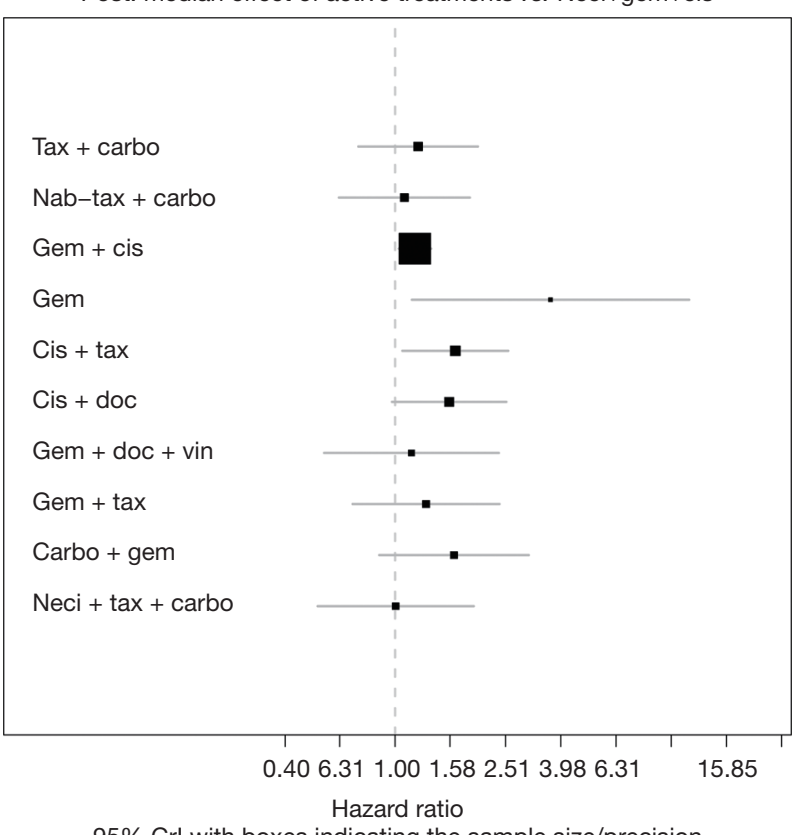

Post. median effect of active treatments vs. Neci+gem+cis

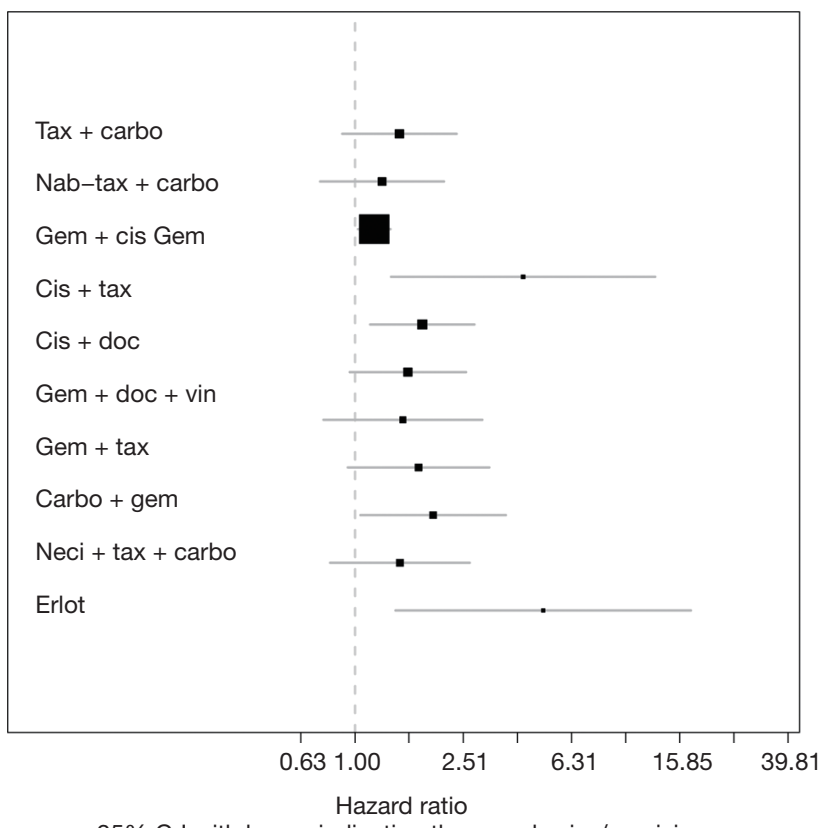

Figure 3 Forest plots showing overall survival (A) and progression-free survival (B) hazard ratio analyses, with (left) and without (right) carbo + S-1. Post, posterior; carbo, carboplatin; cis, cisplatin; CrI, credible interval; doc, docetaxel; erlot, erlotinib; gem, gemcitabine; nabtax, nab-paclitaxel; neci, necitumumab; tax, paclitaxel; vin, vinorelbine.

$(14,25,27,29,34,37,38)$. Also similar to the OS analyses, PFS median analyses were conducted versus tax + carbo because the models failed to converge versus neci + gem + cis.
Consistent with the HR analysis (Figure 3B), neci + gem + cis was associated with a longer PFS than all comparators in the analysis using median PFS data (Figure 5). 


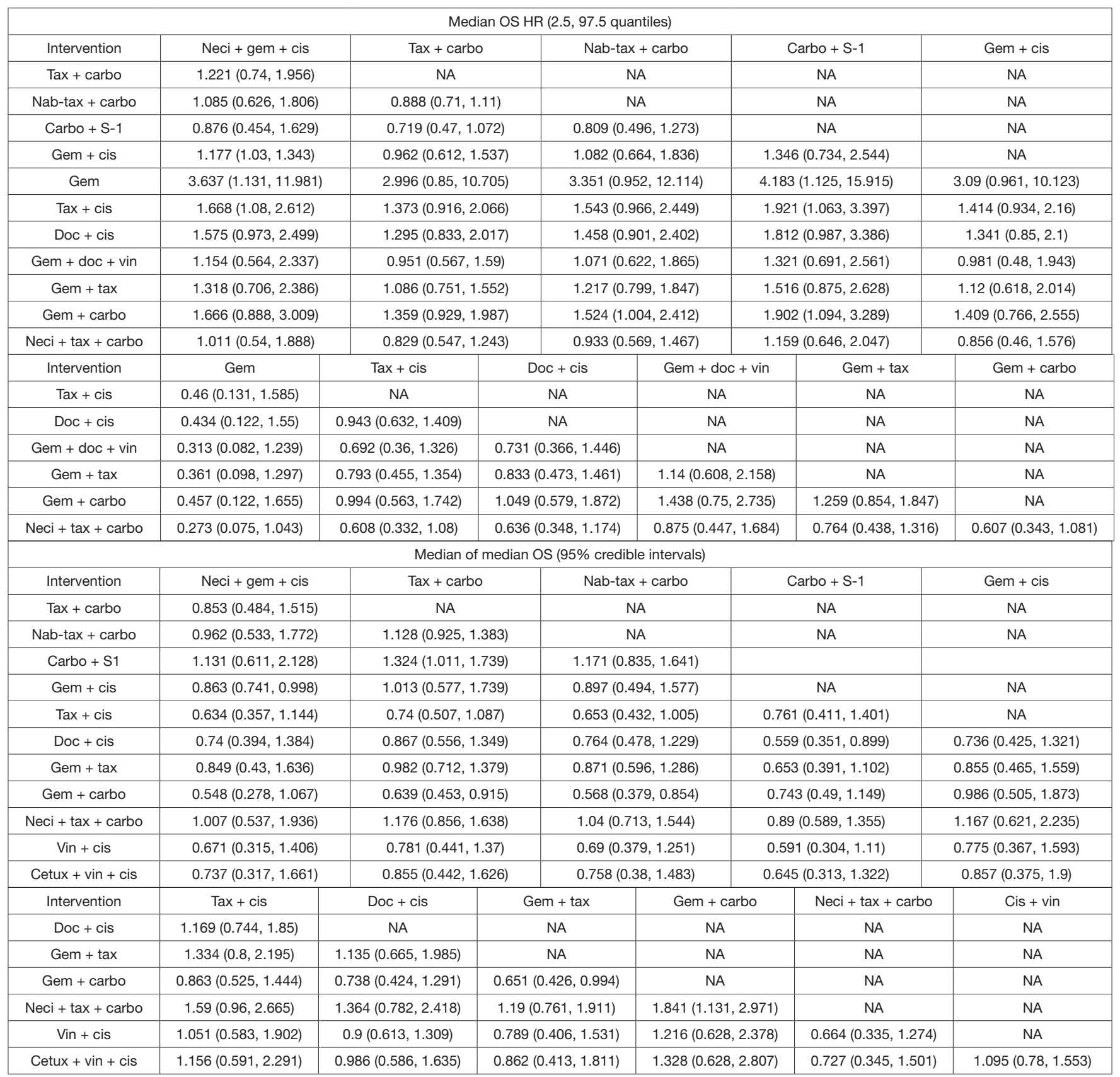

Figure 4 Pairwise comparisons: median OS HR and median of median OS. carbo, carboplatin; cetux, cetuximab; cis, cisplatin; doc, docetaxel; gem, gemcitabine; HR, hazard ratio; nab-tax, nab-paclitaxel; neci, necitumumab; OS, overall survival; tax, paclitaxel; vin, vinorelbine.

\section{Adverse events}

No studies in the network reported toxicity outcomes for the squamous population that enabled comparison with neci + gem + cis; therefore, this analysis could not be conducted.

\section{Quality of life}

QOL data were not collected consistently in the studies included in the meta-analysis; therefore, no analyses could be conducted for this outcome. 


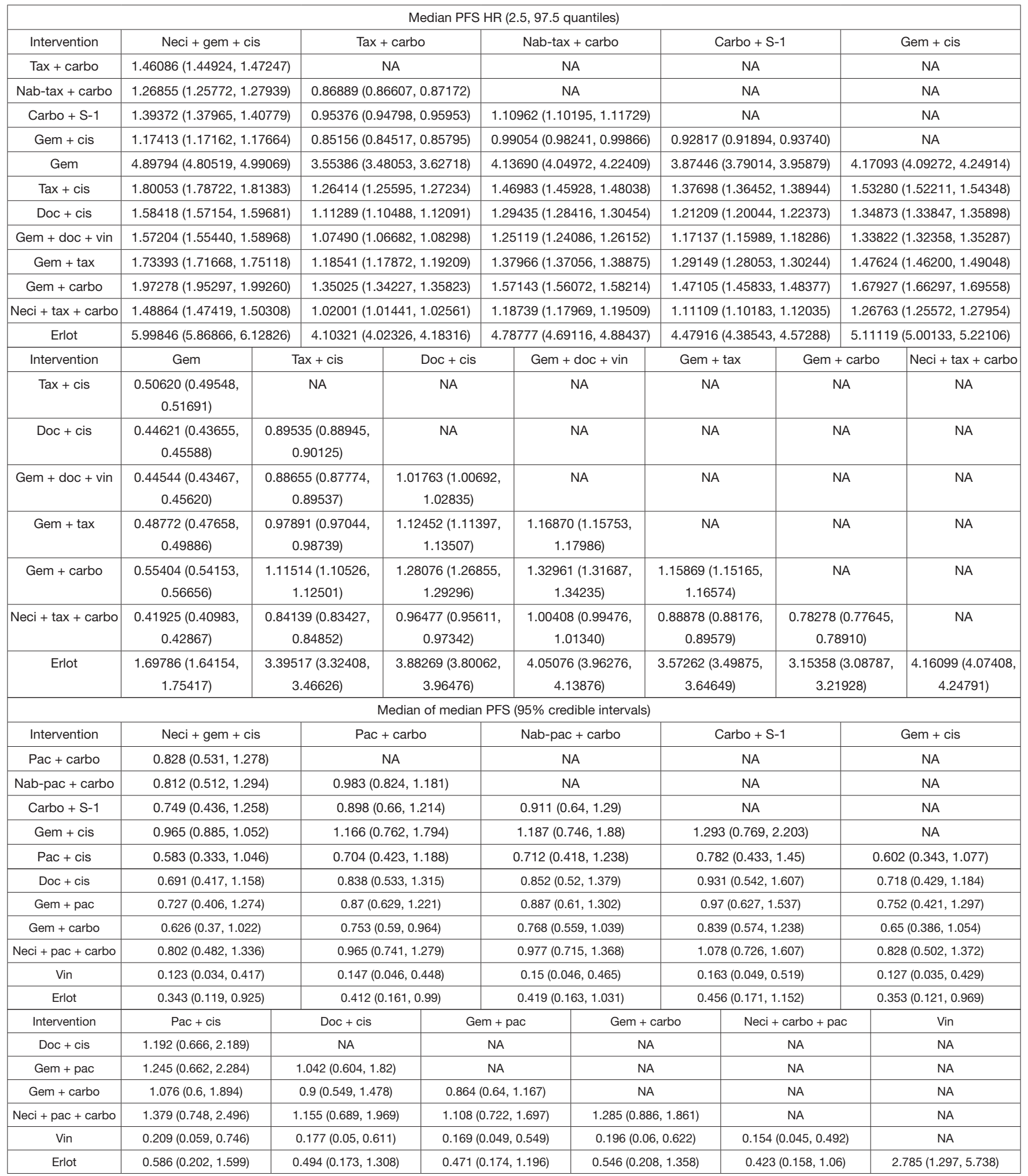

Figure 5 Pairwise comparisons: median PFS HR and median of median PFS. carbo, carboplatin; cis, cisplatin; doc, docetaxel; erlot, erlotinib; gem, gemcitabine; HR, hazard ratio; nab-tax, nab-paclitaxel; neci, necitumumab; PFS, progression-free survival; tax, paclitaxel; vin, vinorelbine. 


\section{Sensitivity analyses}

The Frequentist analysis demonstrated consistent findings with the primary Bayesian analyses: all regimens other than carbo + S-1 had a higher HR for OS than neci + gem + cis, and all regimens had a higher HR for PFS than neci + gem + cis (Table S2). All other pre-planned sensitivity analyses could not be conducted due to fragmentation of the network. BDue to the limited evidence for each comparator, the removal of any single study resulted in the inability to connect remaining trials via the study network.

\section{Heterogeneity and inconsistency}

Wide CrIs were observed in the Morabito et al. (30) study (OS and PFS HR analyses) and for Lilenbaum et al. (29) (PFS HR analysis). Sensitivity analyses were conducted in which these studies were removed to reduce heterogeneity. The results did not change for neci + gem + cis because it was not central to the study network and simply reduced the number of comparators evaluated. The consistency assumption could not be explored because of the lack of closed loops in the network that included neci + gem + cis.

\section{Discussion}

There is much uncertainty regarding the results presented in this network meta-analysis of first-line treatments for patients with advanced or metastatic squamous NSCLC. This uncertainty is attributed to the limited number of studies eligible for inclusion in this analysis and the additional limitation of analyzing subpopulations from the majority of the trials included in the analyses (generally, the squamous population was less than $30 \%$ of the total study population for most of the studies identified in the literature search). Wide credible intervals were observed and there was difficulty in clearly distinguishing survival outcomes among comparators for either HR or median survival estimates. As stated previously, many comparators in the network were supported by only one study. The evidence networks were analyzed via a single pairwise metaanalysis and as a series of indirect comparisons. Only two studies provided direct comparative data with neci +gem + cis $(14,35)$. Adding to the limited data, indirect comparison estimates further increased uncertainty with each additional link in the evidence network. In some cases, up to four links were required to reach a comparison versus neci + gem + cis. The planned analyses of toxicity and QOL data could not be conducted due to limited data, which further adds to the uncertainty of the clinical implications of these findings. Additionally, most of the planned sensitivity analyses were not possible due to fragmentation of the network, so the stability of the findings across these scenarios remains unknown. Importantly, each of the agents included in this study has a unique toxicity profile, but the lack of consistent data made the network meta-analysis of grade 3-4 adverse events impossible to conduct. The eligible studies identified in this search only reported toxicity outcomes for the overall population rather than separately by histologic subgroups, thus it is not possible to know which adverse events were experienced by patients with squamous NSCLC, as per the objective of this study. As a result, providers should understand the unique toxicity profiles of each regimen when considering treatment alternatives because indirect comparisons could not be conducted as planned in this study.

This meta-analysis further demonstrates the clinical unmet need for patients with squamous NSCLC. Few treatment options exist in the first-line setting, and patients have limited options for care with treatment regimens that have demonstrated clinical efficacy. In addition to demonstrating the paucity of research for the treatment of patients with squamous NSCLC, the data from this metaanalysis may provide additional evidence for selecting among available treatment options. However, it is important to note that survival gains demonstrated in this work were only modest and there remains a need to develop better approaches to prolong both PFS and OS among patients diagnosed with metastatic squamous NSCLC.

The methodological quality review and risk of bias assessments using the PEDro and Cochrane criteria, respectively, suggested that most of the studies included in the systematic literature review were rated as high quality with a low risk of bias. Blinding was the most common negatively rated criterion; however, blinding is not practical in many oncology trials because therapies are often administered using different schedules and infusion rates, making it difficult to conceal the identity of the study drug.

While considering the limitations of the available data and this analysis, the results of the network meta-analysis suggest that both carbo $+\mathrm{S}-1$ and neci + gem + cis may have clinical benefit versus the comparators included in the analysis. $\mathrm{Neci}+$ gem + cis and carbo $+\mathrm{S}-1$ both have a high probability of ranking high for OS outcomes, and neci + gem + cis has a high probability of ranking high for PFS. 
Carbo + S-1 is only approved for the treatment of NSCLC in Asia, so, at this time, patients in other areas of the world do not have access to this therapy. Consistent with the evidence published by Spigel and colleagues (35), neci in combination with carbo + paclitaxel did not demonstrate improved efficacy; the FDA-approved combination with gem + cis remains the regimen that has demonstrated efficacy with necitumumab in squamous NSCLC. Despite the potentially improved outcomes of both carbo $+\mathrm{S}-1$ and neci + gem + cis versus other comparators, the findings should be interpreted with caution due to the limitations stated here.

This meta-analysis was designed to evaluate randomized trials reporting survival data for patients with squamous NSCLC connected by an evidence network to neci + gem + cis, to allow for the comparison of this new regimen versus other active therapies that have not been studied in headto-head trials. In many cases, this was only a subpopulation of the trial sample, which could have reduced statistical rigor. Additionally, because most trials were not stratified by histology, the randomization may not have been balanced among groups for the squamous subpopulation. The selection of treatment by histology is a relatively recent development. The scope of data included in this analysis were planned to be broad given the anticipated gaps in trials conducted among the squamous population. As a result, some comparators (e.g., cetuximab) may have little relevance post-2015. When the study protocol was developed (16), cetuximab was included in National Comprehensive Cancer Network (NCCN) treatment guidelines in the United States; however, in 2015, the use of cetuximab was removed from the guidelines because of toxicity and limited efficacy (7). Similarly, two studies that were used to contribute data for survival outcomes of erlotinib should be viewed with caution as these were very small phase II studies $(\mathrm{n} \leq 30)(27,29)$; a very small number of squamous NSCLC patients are EGFR mutation positive, thus few are eligible to receive this therapy. This analysis did not account for mutation status, as it was not reported in the included trials.

HR data were included in the primary analysis of survival. A pooled HR is usually calculated assuming proportional hazards, which implies that although the individual treatment hazards may vary over time, the hazard of the event for one group at any time point is proportional to the hazard in the second group. Because a number of studies did not provide HR data, some HRs were estimated from digitization and analysis of published survival curves. The pre-planned analysis using median survival data allowed an indirect comparison with additional comparators, such as vinorelbine + cis, which was not possible with HR data alone. However, not all studies reported median data, so most comparators could only be compared in one of the two planned analyses, providing additional challenges to interpretation of data.

\section{Conclusions}

Results of this clinical-trial based network meta-analysis suggest that carboplatin plus S-1 and necitumumab in combination with gemcitabine and cisplatin may have OS benefits versus other regimens and that necitumumab in combination with gemcitabine and cisplatin may also have PFS benefits versus other comparators. However, these results should be interpreted with caution due to the limited number of studies, few of which focused exclusively on squamous NSCLC, the inability to adjust for covariates, and the wide credible intervals. Data were not available to conduct a network meta-analysis of either toxicity or QOL.

\section{Acknowledgements}

This work was supported by Eli Lilly and Company.

\section{Footnote}

Conflicts of Interest: All authors are employees or retired employees of Eli Lilly and Company.

Financial Disclosure: The following hold equity in Eli Lilly and Company: Fanni Natanegara, Victoria Soldatenkova, Alan Brnabic, Jacqueline Brown.

\section{References}

1. Erikson HS, Wistuba II. Pathology of lung cancer. Lung Cancer: A Multidisciplinary Approach to Diagnosis and Management. Demos Medical Publishing, LLC, 2010.

2. Kim HS, Mitsudomi T, Soo RA, et al. Personalized therapy on the horizon for squamous cell carcinoma of the lung. Lung Cancer 2013;80:249-55.

3. Cohen MH, Johnson JR, Wang YC, et al. FDA drug approval summary: pemetrexed for injection (Alimta) for the treatment of non-small cell lung cancer. Oncologist 2005;10:363-8.

4. Gebbia V, Galetta D, De Marinis F. Non small cell lung 
cancer patients with ECOG PS2: unsolved questions and lessons from clinical trials. Ann Oncol 2005;16 Suppl 4:iv123-31.

5. Cetin K, Ettinger DS, Hei YJ, et al. Survival by histologic subtype in stage IV nonsmall cell lung cancer based on data from the Surveillance, Epidemiology and End Results Program. Clin Epidemiol 2011;3:139-48.

6. Reck M, Popat S, Reinmuth N, et al. Metastatic nonsmall-cell lung cancer (NSCLC): ESMO Clinical Practice Guidelines for diagnosis, treatment and follow-up. Ann Oncol 2014;25 Suppl 3:iii27-39.

7. NCCN. NCCN Clinical Practice Guidelines in Oncology: Non-Small Cell Lung Cancer, Version 7.2015. 2015. Available online: http://www.nccn.org/professionals/ physician_gls/pdf/nscl.pdf. Accessed September 28, 2015.

8. Oliver TG, Patel J, Akerley W. Squamous non-small cell lung cancer as a distinct clinical entity. Am J Clin Oncol 2015;38:220-6.

9. NCCN. NCCN Clinical Practice Guidelines in Oncology: Non-small cell lung cancer v5.2018. 2018. Available online: http://www.nccn.org/professionals/physician_gls/ pdf/nscl.pdf. Accessed July 20, 2018.

10. Villaruz LC, Socinski MA. Is there a role of nab-paclitaxel in the treatment of advanced non-small cell lung cancer? The data suggest yes. Eur J Cancer 2016;56:162-71.

11. Paz-Ares LG, Luft A, Tefreshi A, et al. Phase 3 study of carboplatin-paclitaxel/nab-paclitaxel (Chemo) with or without pembrolizumab (Pembro) for patients (Pts) with metastatic squamous $(\mathrm{Sq})$ non-small cell lung cancer (NSCLC). J Clin Oncol 2018;36 suppl:abstr 105.

12. Paz-Ares LG, Luft A, Tefreshi A, et al. KEYNOTE 407: Phase 3 study of carboplatin-paclitaxel/nab-paclitaxel with or without pembrolizumab for metastatic squamous NSCLC. ASCO Annual Meeting 2018.

13. Hess LM, Able SL, Carter GC, et al. Innovation in Non-Small Cell Lung Cancer (NSCLC): Where are the clinically meaningful outcomes? . 16th World Conference on Lung Cancer; 2015; Denver, CO.

14. Thatcher N, Hirsch FR, Luft AV, et al. Necitumumab plus gemcitabine and cisplatin versus gemcitabine and cisplatin alone as first-line therapy in patients with stage IV squamous non-small-cell lung cancer (SQUIRE): an open-label, randomised, controlled phase 3 trial. Lancet Oncol 2015;16:763-74.

15. DeLozier AM, Brown J, Natanegara F, et al. Study protocol: systematic review and meta-analysis of randomized controlled trials in first-line treatment of squamous non-small cell lung cancer. Syst Rev 2014;3:102.
16. Hutton B, Salanti G, Caldwell DM, et al. The PRISMA extension statement for reporting of systematic reviews incorporating network meta-analyses of health care interventions: checklist and explanations. Ann Intern Med 2015;162:777-84.

17. Moher D, Liberati A, Tetzlaff J, et al. Preferred reporting items for systematic reviews and meta-analyses: the PRISMA statement. PLoS Med 2009;6:e1000097.

18. Maher CG, Sherrington C, Herbert RD, et al. Reliability of the PEDro scale for rating quality of randomized controlled trials. Phys Ther 2003;83:713-21.

19. Higgins JP, Altman DG, Gotzsche PC, et al. The Cochrane Collaboration's tool for assessing risk of bias in randomised trials. BMJ 2011;343:d5928.

20. Sutton AJ, Abrams KR. Bayesian methods in metaanalysis and evidence synthesis. Stat Methods Med Res 2001;10:277-303.

21. Collett D. Modelling Survival Data in Medical Research, Third Edition. CRC Press; 2015.

22. Rucker G. Network meta-analysis, electrical networks and graph theory. Res Synth Methods 2012;3:312-24.

23. Krahn U, Binder H, Konig J. A graphical tool for locating inconsistency in network meta-analyses. BMC Med Res Methodol 2013;13:35.

24. Govindan R, Bogart J, Stinchcombe T, et al. Randomized phase II study of pemetrexed, carboplatin, and thoracic radiation with or without cetuximab in patients with locally advanced unresectable non-small-cell lung cancer: Cancer and Leukemia Group B trial 30407. J Clin Oncol 2011;29:3120-5.

25. Hoang T, Dahlberg SE, Schiller JH, et al. Does histology predict survival of advanced non-small cell lung cancer patients treated with platin-based chemotherapy? An analysis of the Eastern Cooperative Oncology Group Study E1594. Lung Cancer 2013;81:47-52.

26. Spigel DR, Kim ES, Lynch T, et al. Randomized phase III trial of gemcitabine (G)/carboplatin (C) with or without iniparib (I) in patients (PTS) with previously untreated stage IV squamous lung cancer. J Thorac Oncol 2013;8:O15.06.

27. Chen YM, Tsai CM, Fan WC, et al. Phase II randomized trial of erlotinib or vinorelbine in chemonaive, advanced, non-small cell lung cancer patients aged 70 years or older. J Thorac Oncol 2012;7:412-8.

28. Kubota K, Kawahara M, Ogawara M, et al. Vinorelbine plus gemcitabine followed by docetaxel versus carboplatin plus paclitaxel in patients with advanced non-small-cell lung cancer: a randomised, open-label, phase III study. 
Lancet Oncol 2008;9:1135-42.

29. Lilenbaum R, Axelrod R, Thomas S, et al. Randomized phase II trial of erlotinib or standard chemotherapy in patients with advanced non-small-cell lung cancer and a performance status of 2. J Clin Oncol 2008;26:863-9.

30. Morabito A, Gebbia V, Di Maio M, et al. Randomized phase III trial of gemcitabine and cisplatin vs. gemcitabine alone in patients with advanced non-small cell lung cancer and a performance status of 2: the CAPPA-2 study. Lung Cancer 2013;81:77-83.

31. Pirker R, Pereira JR, Szczesna A, et al. Cetuximab plus chemotherapy in patients with advanced non-small-cell lung cancer (FLEX): an open-label randomised phase III trial. Lancet 2009;373:1525-31.

32. Pirker R, Pereira JR, von Pawel J, et al. EGFR expression as a predictor of survival for first-line chemotherapy plus cetuximab in patients with advanced non-small-cell lung cancer: analysis of data from the phase 3 FLEX study. Lancet Oncol 2012;13:33-42.

33. Gatzemeier U, von Pawel J, Vynnychenko I, et al. Firstcycle rash and survival in patients with advanced non-smallcell lung cancer receiving cetuximab in combination with first-line chemotherapy: a subgroup analysis of data from the FLEX phase 3 study. Lancet Oncol 2011;12:30-7.

34. Socinski MA, Bondarenko I, Karaseva NA, et al. Weekly nab-paclitaxel in combination with carboplatin versus solvent-based paclitaxel plus carboplatin as first-line therapy in patients with advanced non-small-cell lung cancer: final results of a phase III trial. J Clin Oncol 2012;30:2055-62.

35. Spigel DR, Luft A, Depenbrock H, et al. An Open-Label, Randomized, Controlled Phase II Study of PaclitaxelCarboplatin Chemotherapy With Necitumumab Versus Paclitaxel-Carboplatin Alone in First-Line Treatment of Patients With Stage IV Squamous Non-Small-Cell Lung Cancer. Clin Lung Cancer 2017;18:480-8.

36. Tan EH, Rolski J, Grodzki T, et al. Global Lung Oncology Branch trial 3 (GLOB3): final results of a randomised multinational phase III study alternating oral and i.v. vinorelbine plus cisplatin versus docetaxel plus cisplatin as first-line treatment of advanced non-small-cell lung cancer. Ann Oncol 2009;20:1249-56.

37. Treat J, Edelman MJ, Belani CP, et al. A retrospective analysis of outcomes across histological subgroups in a three-arm phase III trial of gemcitabine in combination with carboplatin or paclitaxel versus paclitaxel plus carboplatin for advanced non-small cell lung cancer. Lung Cancer 2010;70:340-6.
38. Yoshioka H, Okamoto I, Morita S, et al. Efficacy and safety analysis according to histology for S-1 in combination with carboplatin as first-line chemotherapy in patients with advanced non-small-cell lung cancer: updated results of the West Japan Oncology Group LETS study. Ann Oncol 2013;24:1326-31.

39. Groen HJ, Sietsma H, Vincent A, et al. Randomized, placebo-controlled phase III study of docetaxel plus carboplatin with celecoxib and cyclooxygenase-2 expression as a biomarker for patients with advanced nonsmall-cell lung cancer: the NVALT-4 study. J Clin Oncol 2011;29:4320-6.

40. Jelic S, Mitrovic L, Radosavljevic D, et al. Survival advantage for carboplatin substituting cisplatin in combination with vindesine and mitomycin $\mathrm{C}$ for stage IIIB and IV squamous-cell bronchogenic carcinoma: a randomized phase III study. Lung Cancer 2001;34:1-13.

41. Lynch TJ, Patel T, Dreisbach L, et al. Cetuximab and first-line taxane/carboplatin chemotherapy in advanced non-small-cell lung cancer: results of the randomized multicenter phase III trial BMS099. J Clin Oncol 2010;28:911-7.

42. Sculier JP. A phase III randomised study comparing two different dose-intensity regimens as induction chemotherapy followed by thoracic irradiation in patients with advanced locoregional non-small-cell lung cancer. Ann Oncol 2004;15:399-409.

43. Gregorc V, Zilembo N, Grossi F, et al. Randomized phase II trial of NGR-hTNF in combination with standard chemotherapy in previously untreated non-small cell lung cancer (NSCLC). ASCO Meeting Abstracts 2013;31:8035.

44. Heymach JV, Paz-Ares L, De Braud F, et al. Randomized phase II study of vandetanib alone or with paclitaxel and carboplatin as first-line treatment for advanced non-smallcell lung cancer. J Clin Oncol 2008;26:5407-15.

45. Langer CJ, Novello S, Park K, et al. Randomized, phase III trial of first-line figitumumab in combination with paclitaxel and carboplatin versus paclitaxel and carboplatin alone in patients with advanced non-small-cell lung cancer. J Clin Oncol 2014;32:2059-66.

46. Lara PN Jr, Douillard JY, Nakagawa K, et al. Randomized phase III placebo-controlled trial of carboplatin and paclitaxel with or without the vascular disrupting agent vadimezan (ASA404) in advanced non-small-cell lung cancer. J Clin Oncol 2011;29:2965-71.

47. Lynch TJ, Bondarenko I, Luft A, et al. Ipilimumab in combination with paclitaxel and carboplatin as first-line treatment in stage IIIB/IV non-small-cell lung cancer: 
results from a randomized, double-blind, multicenter phase II study. J Clin Oncol 2012;30:2046-54.

48. Novello S, Scagliotti GV, Sydorenko O, et al. Motesanib plus carboplatin/paclitaxel in patients with advanced squamous non-small-cell lung cancer: results from the randomized controlled MONET1 study. J Thorac Oncol 2014;9:1154-61.

49. Paz-Ares L, Balint B, de Boer RH, et al. A randomized phase 2 study of paclitaxel and carboplatin with or without conatumumab for first-line treatment of advanced nonsmall-cell lung cancer. J Thorac Oncol 2013;8:329-37.

50. Reck M, Krzakowski M, Chmielowska E, et al. A randomized, double-blind, placebo-controlled phase 2 study of tigatuzumab (CS-1008) in combination with carboplatin/paclitaxel in patients with chemotherapy-naive metastatic/unresectable non-small cell lung cancer. Lung Cancer 2013;82:441-8.

51. Scagliotti G, Novello S, von Pawel J, et al. Phase III study of carboplatin and paclitaxel alone or with sorafenib in advanced non-small-cell lung cancer. J Clin Oncol 2010;28:1835-42.

52. von Pawel J, Gorbounova V, Reck M, et al. DISRUPT: a randomised phase 2 trial of ombrabulin (AVE8062) plus a taxane-platinum regimen as first-line therapy for metastatic non-small cell lung cancer. Lung Cancer 2014;85:224-9.

53. Sandler A, Yi J, Dahlberg S, et al. Treatment outcomes by tumor histology in Eastern Cooperative Group Study E4599 of bevacizumab with paclitaxel/carboplatin for advanced non-small cell lung cancer. J Thorac Oncol 2010;5:1416-23.

54. Scagliotti GV, Park K, Patil S, et al. Survival without toxicity for cisplatin plus pemetrexed versus cisplatin plus gemcitabine in chemonaive patients with advanced nonsmall cell lung cancer: a risk-benefit analysis of a large phase III study. Eur J Cancer 2009;45:2298-303.

55. Novello S, Pimentel FL, Douillard JY, et al. Safety and resource utilization by non-small cell lung cancer histology: results from the randomized phase III study of pemetrexed plus cisplatin versus gemcitabine plus cisplatin in chemonaive patients with advanced non-small cell lung cancer. J Thorac Oncol 2010;5:1602-8.

56. Johnson DH, Fehrenbacher L, Novotny WF, et al. Randomized phase II trial comparing bevacizumab plus carboplatin and paclitaxel with carboplatin and paclitaxel alone in previously untreated locally advanced or metastatic non-small-cell lung cancer. J Clin Oncol 2004;22:2184-91.

57. Schuette WH, Groschel A, Sebastian M, et al. A randomized phase II study of pemetrexed in combination with cisplatin or carboplatin as first-line therapy for patients with locally advanced or metastatic non-small-cell lung cancer. Clin Lung Cancer 2013;14:215-23.

58. Zhang X, Lu J, Xu J, et al. Pemetrexed plus platinum or gemcitabine plus platinum for advanced non-small cell lung cancer: final survival analysis from a multicentre randomized phase II trial in the East Asia region and a meta-analysis. Respirology 2013;18:131-9.

59. Lee SM, Rudd R, Woll PJ, et al. Randomized double-blind placebo-controlled trial of thalidomide in combination with gemcitabine and Carboplatin in advanced non-smallcell lung cancer. J Clin Oncol 2009;27:5248-54.

60. Zwitter M, Kovac V, Smrdel U, et al. Gemcitabine in brief versus prolonged low-dose infusion, both combined with cisplatin, for advanced non-small cell lung cancer: a randomized phase II clinical trial. J Thorac Oncol 2009;4:1148-55.

61. Spigel D, Luft A, Ramlau R, et al. A randomized, multicenter, open-label, phase 2 study of paclitaxelcarboplatin (PC) chemotherapy plus necitumumab (IMC-11F8/LY3012211) versus PC alone in the firstline treatment of patients (pts) with stage IV squamous non-small cell lung cancer (sq-NSCLC). Molecular Cancer Therapeutics. Conference: AACR-NCI-EORTC International Conference: Molecular Targets and Cancer Therapeutics 2015 Boston, MA United States. Conference Start: 20151105 Conference End: 20151109. Conference Publication: (var.pagings). 14 (12 SUPPL. 2) (no pagination), 2015. Date of Publication: December $2015 ; 2015$.
Cite this article as: Hess LM, DeLozier AM, Natanegara F, Wang X, Soldatenkova V, Brnabic A, Able SL, Brown J. First-line treatment of patients with advanced or metastatic squamous non-small cell lung cancer: systematic review and network meta-analysis. J Thorac Dis 2018;10(12):6677-6694. doi: $10.21037 / j t d .2018 .11 .87$ 
Supplementary

Table S1 PEDro study quality score and Cochrane risk of bias assessment

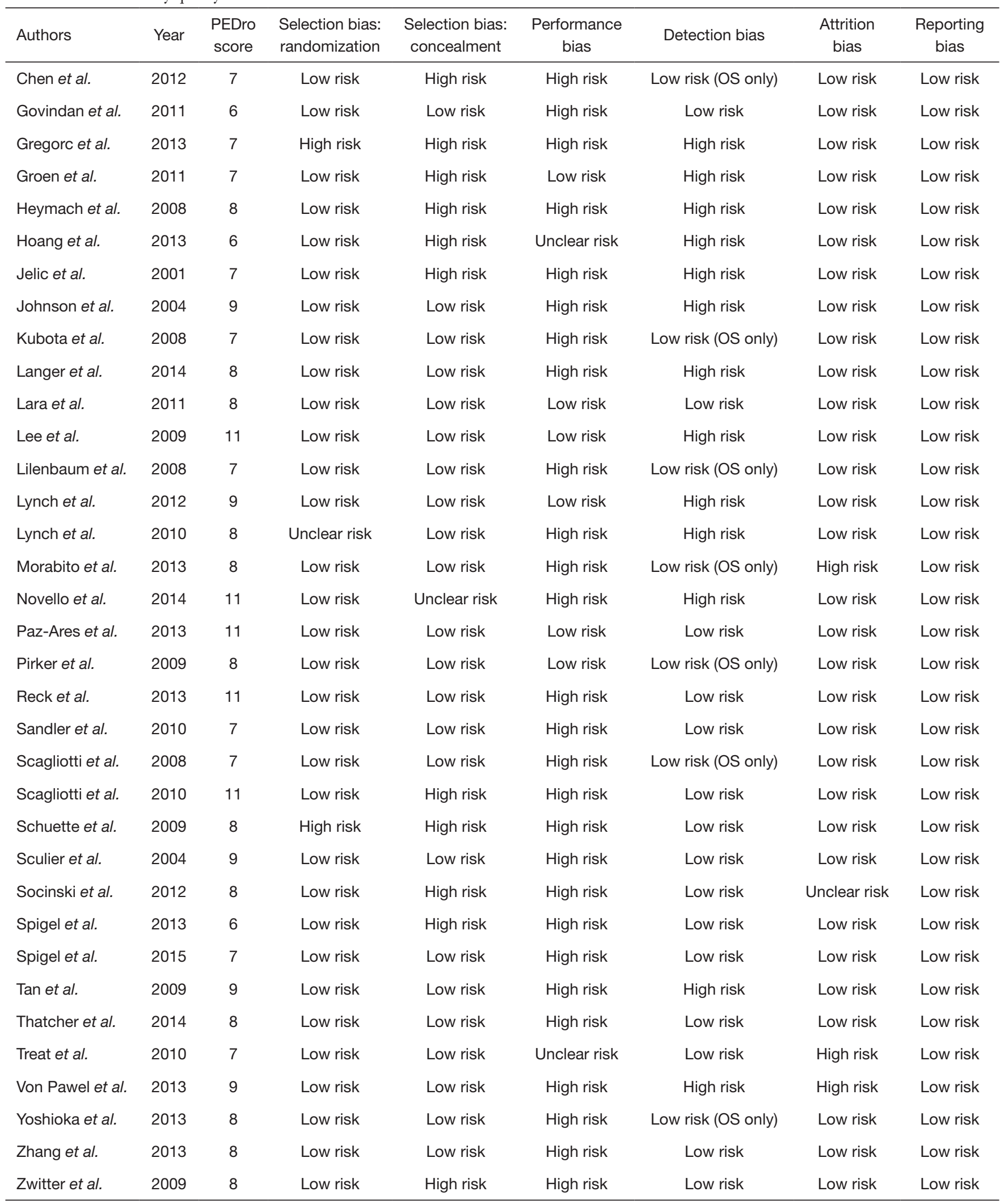

OS, overall survival. 


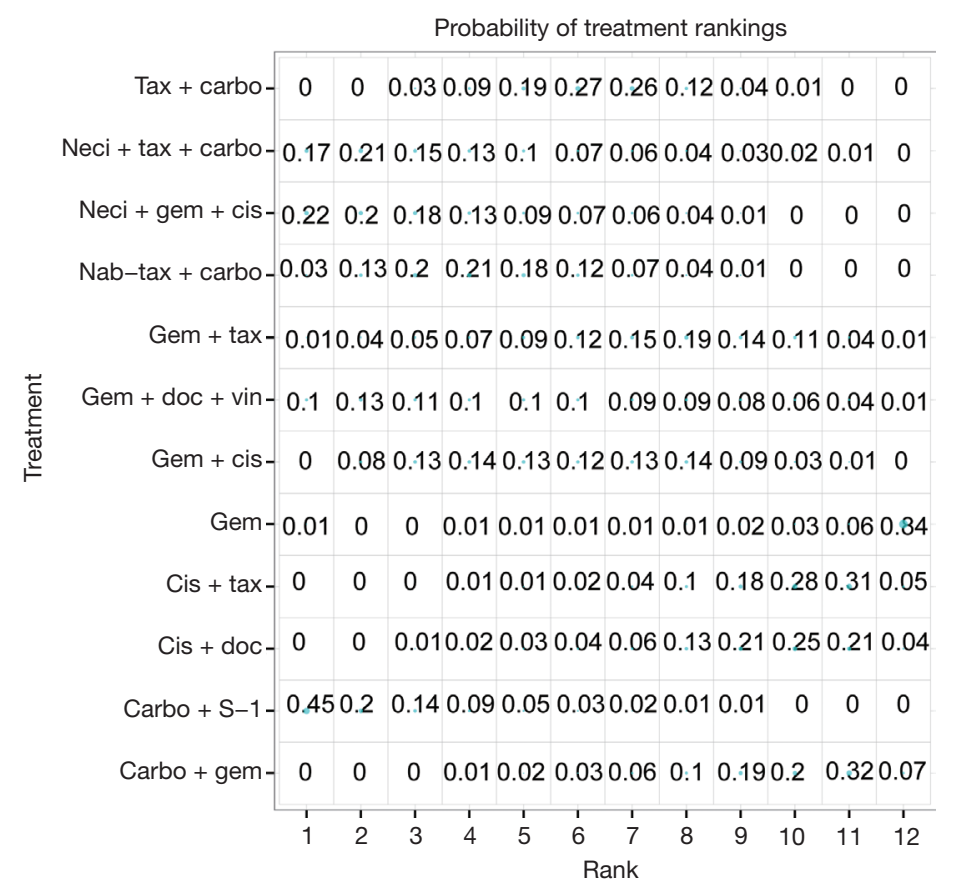

Figure S1 Probability of treatment rankings for the analysis of overall survival, hazard ratio analysis. Carbo, carboplatin; cis, cisplatin; doc, docetaxel; erlot, erlotinib; gem, gemcitabine; nab-tax, nab-paclitaxel; neci, necitumumab; tax, paclitaxel; vin, vinorelbine.

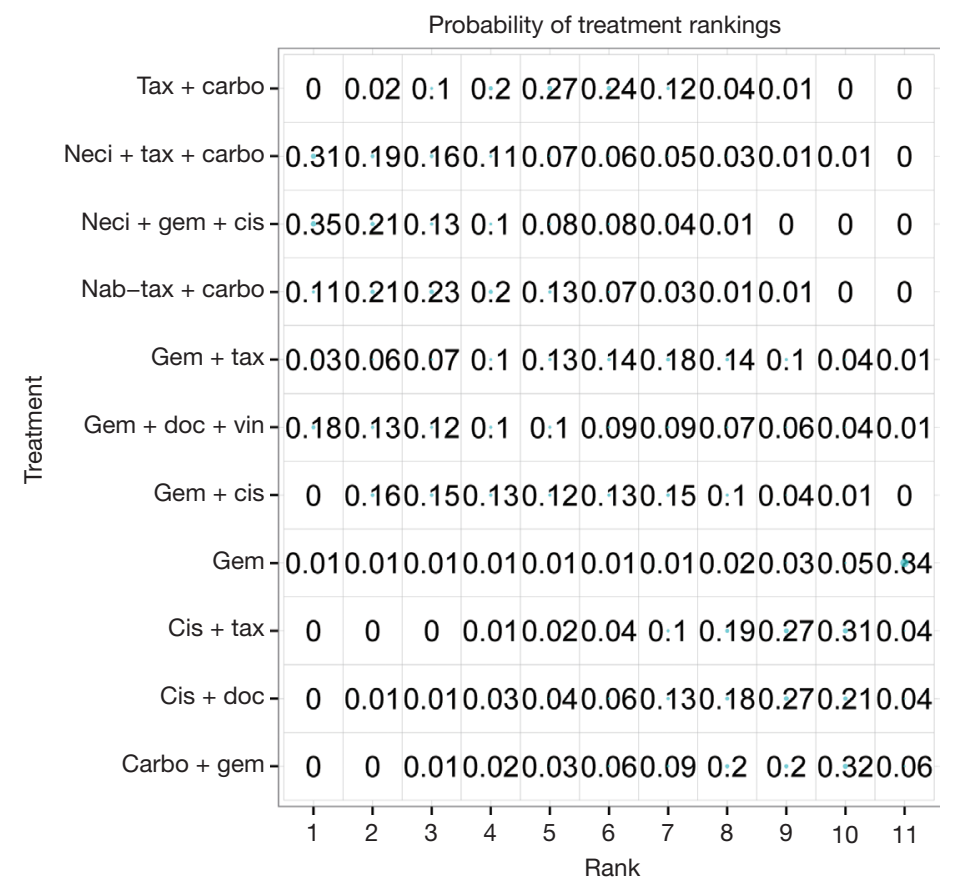

Figure S2 Probability of treatment rankings for the analysis of overall survival, hazard ratio analysis, excluding carbo + S-1. Carbo, carboplatin; cis, cisplatin; doc, docetaxel; erlot, erlotinib; gem, gemcitabine; nab-tax, nab-paclitaxel; neci, necitumumab; tax, paclitaxel; vin, vinorelbine. 


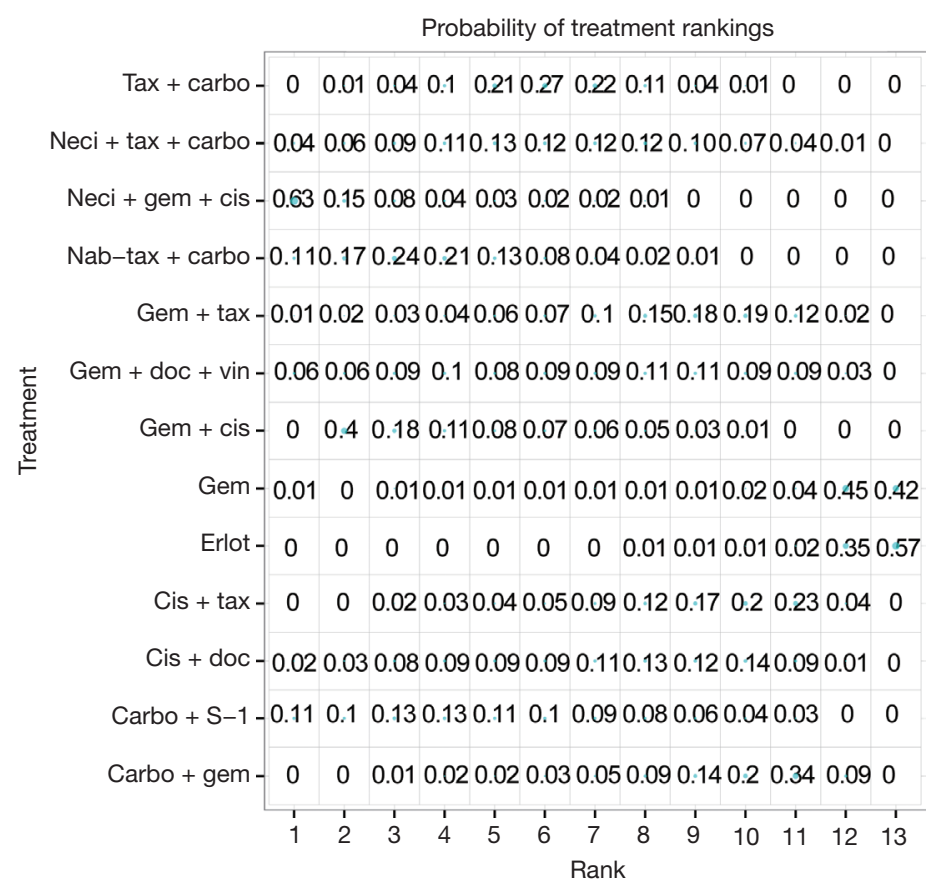

Figure S3 Probability of treatment rankings for the analysis of progression-free survival, hazard ratio analysis. Carbo, carboplatin; cis, cisplatin; doc, docetaxel; erlot, erlotinib; gem, gemcitabine; nab-tax, nab-paclitaxel; neci, necitumumab; tax, paclitaxel; vin, vinorelbine.

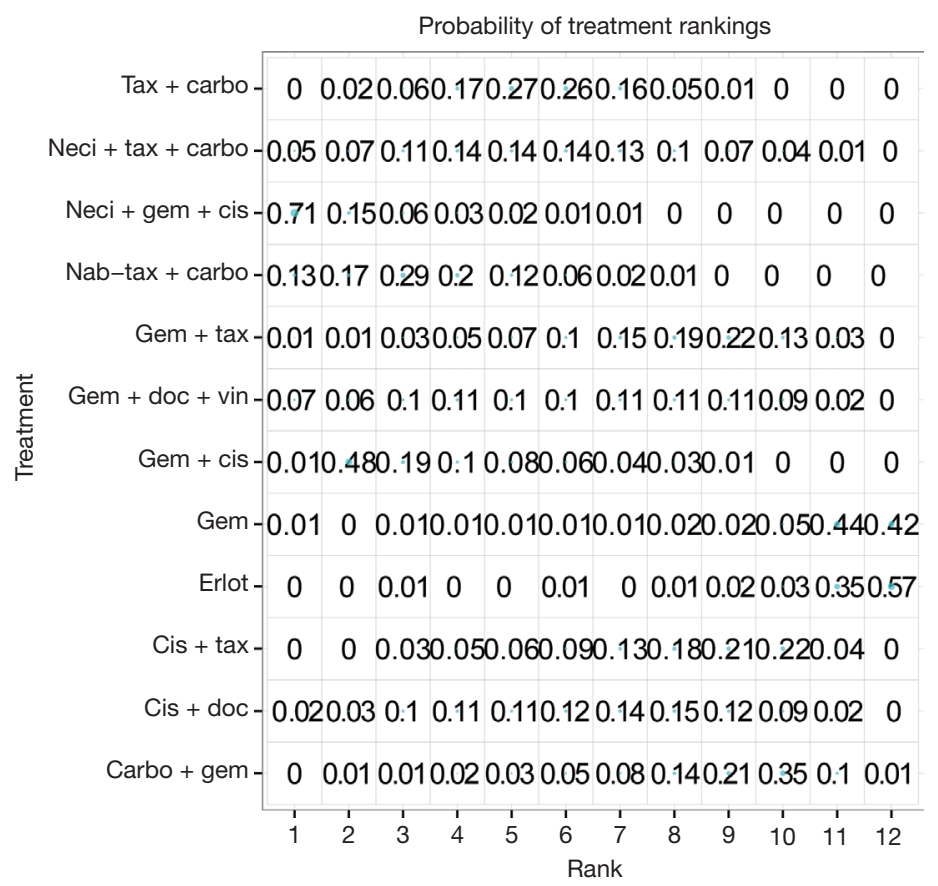

Figure S4 Probability of treatment rankings for the analysis of progression-free survival, hazard ratio analysis, excluding carbo + S-1. Carbo, carboplatin; cis, cisplatin; doc, docetaxel; erlot, erlotinib; gem, gemcitabine; nab-tax, nab-paclitaxel; neci, necitumumab; tax, paclitaxel; vin, vinorelbine. 
Table S2 Comparison of Bayesian and Frequentist results (sensitivity analysis)

\begin{tabular}{lcccc}
\hline & \multicolumn{4}{c}{ Neci + gem + cis } \\
\cline { 2 - 5 } Variables & $\begin{array}{c}\text { Frequentist OS, HR } \\
(95 \% \mathrm{Cl})\end{array}$ & $\begin{array}{c}\text { Bayesian OS, median HR } \\
(95 \% \mathrm{Crl})\end{array}$ & $\begin{array}{c}\text { Frequentist PFS, HR } \\
(95 \% \mathrm{Cl})\end{array}$ & $\begin{array}{c}\text { Bayesian PFS, median HR } \\
(95 \% \text { Crl })\end{array}$ \\
\hline Carbo + gem & $1.53(0.87,2.7)$ & $1.67(0.89,3.01)$ & $1.80(1.01,3.22)$ & $1.97(1.95,1.99)$ \\
Carbo + S-1 & $0.88(0.49,1.6)$ & $0.88(0.45,1.63)$ & $1.27(0.71,2.27)$ & $1.39(1.38,1.41)$ \\
Cis + doc & $1.58(1.02,2.46)$ & $1.58(0.97,2.50)$ & $1.50(0.96,2.36)$ & $1.58(1.57,1.60)$ \\
Cis + tax & $1.67(1.08,2.59)$ & $1.67(1.08,2.61)$ & $1.71(1.10,2.66)$ & $1.80(1.79,1.81)$ \\
Gem & $3.68(1.17,11.6)$ & $3.64(1.13,11.98)$ & $4.19(1.35,13.06)$ & $4.90(4.81,4.99)$ \\
Gem + cis & $1.18(1.03,1.34)$ & $1.18(1.03,1.34)$ & $1.17(1.03,1.34)$ & $1.17(1.17,1.18)$ \\
Gem + doc + vin & $1.16(0.59,2.28)$ & $1.15(0.56,2.34)$ & $1.41(0.74,2.69)$ & $1.57(1.55,1.59)$ \\
Gem + tax & $1.26(0.72,2.23)$ & $1.32(0.71,2.39)$ & $1.58(0.90,2.80)$ & $1.73(1.72,1.75)$ \\
Nab-tax + carbo & $1.1(0.68,1.79)$ & $1.09(0.63,1.81)$ & $1.17(0.72,1.91)$ & $1.270(1.26,1.28)$ \\
Neci + tax + carbo & $1.03(0.56,1.87)$ & $1.01(0.54,1.89)$ & $1.35(0.77,2.38)$ & $1.49(1.475,1.50)$ \\
Tax + carbo & $1.24(0.8,1.91)$ & $1.22(0.74,1.96)$ & $1.35(0.87,2.11)$ & $1.46(1.45,1.47)$ \\
\hline
\end{tabular}

Carbo, carboplatin; $\mathrm{Cl}$, confidence interval; cis, cisplatin; Crl, credible interval; doc, docetaxel; gem, gemcitabine; HR, hazard ratio; nabtax, nab-paclitaxel; neci, necitumumab; OS, overall survival; PFS, progression-free survival; tax, paclitaxel; vin, vinorelbine. 